The best solvent for it is hot alcohol. Both these sulfocyanates should be handled with care, as they have an irritating action on the skin, which in extreme cases may cause serious poisoning.

Cambridge, Mass.

[CONTRIBUTION FROM ChEMICAL LABORATORY OF JOHNS HOPKINS UNIVERSiTY.]

\title{
STUDIES IN ESTERIFICATION. VI. THE ESTERIFICATION OF BENZOIC ACID BY MERCAPTANS.
}

By L. S. PRATr AND E. EMMET REID.

Received May 8, 1915.

Introduction.

A study of the elements in any group of the periodic system reveals certain analogies and certain contrasts in their behavior. Both analogies and contrasts are found when we compare organic oxygen and sulfur derivatives.

One of the most studied organic reactions is that of esterification, while but little attention has been devoted to the esterification of any but oxygen alcohols.

The study of the esterification of sulfur alcohols was taken up in the hope of throwing light on the theory of esterification, and of comparing mercaptans, or sulfur alcohols, with oxygen alcohols.

\section{Historical.}

The classical experiments of Berthelot and Pean de St. Gilles, ${ }^{1}$ and the more exact work of Menschutkin ${ }^{2}$ and Lichty ${ }^{3}$ have shown that, when an alcohol is heated with an acid, esterification takes place and a well-defined limit is reached, and that the same limit may be reached by heating the corresponding ester with water.

\section{(I) $\mathrm{CH}_{3} \mathrm{COOH}+\mathrm{HOC}_{2} \mathrm{H}_{5} \rightleftarrows \mathrm{CH}_{3} \mathrm{COOC}_{2} \mathrm{H}_{5}+\mathrm{HOH}$.}

The following values from the work of Menschutkin ${ }^{4}$ show the limits obtained by heating acetic acid and alcohols in equimolecular quantities, at $154^{\circ}$ :

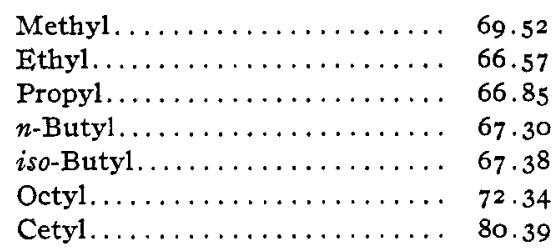

If these results are plotted as a curve, ethyl alcohol is found at the minimum, the limits increasing gradually with the molecular weights

I Am. Chem. Pharm., [3] 65, 385-422 (1862);66, 5-218 (1862);68, 225-359 (1863).

${ }^{2}$ Ber., II, I507 (I878); I0, 1728 (I877).

'Am. Chem. J., 17, 27 (1895); 18, 590 (1896).

4 Ber. II, I5 Io (1878). 
of the alcohols. Methyl alcohol, however, instead of giving a limit below that reached by ethyl alcohol, shows a value corresponding roughly to that for heptyl alcohol. This is, however, in keeping with the ustral abnormal behavior of the substance.

The effect of temperature on the limit of esterification has been the subject of considerable discussion, and even at the present time there is some uncertainty as to the facts in the case.

Menschutkin, ${ }^{1}$ in 1884 , quoted Berthelot as showing that no change in the limit of esterification is found with change in temperature, and confirmed this by his own results. However, he showed that in the case of amides the limit is considerably raised by elevation of temperature, while in the case of anilides, the limit decreases quite appreciably.

On the other hand, Sabatier and Maihle ${ }^{2}$ quote the following values from the work of Berthelot, showing that the limit, in the esterification of acetic acid by ethyl alcohol, in equimolecular quantities, is not definitely fixed, but that it gradually changes with change in temperature:

$\begin{array}{ccl}\text { Temperature. } & \text { Time. } & \text { Limit. } \\ \text { At room temperature } & \text { I6 years } & 65.2 \% \\ 100^{\circ} & 200 \text { hours } & 65.6 \\ 170^{\circ} & 42 \text { hours } & 66.5 \\ 200^{\circ} & 24 \text { hours } & 67.3\end{array}$

They confirm these by giving data, obtained with other alcohols and acids, at $280-300^{\circ}$, showing that at these temperatures the limits are appreciably higher than at lower temperatures.

It is an important and interesting fact that the limits, for various acids and many primary alcohols, obtained at the same temperature are all nearly alike, varying not widely from $66 \%$.

Using benzoic acid and ethyl alcohol, Berthelot ${ }^{3}$ and Pean de St. Gilles obtained $66.5 \%$ as the limit, which is practically identical with the value $66.57 \%$ found by Menschutkin for acetic acid and ethyl alcohol.

Secondary and tertiary alcohols give widely different limits and here again it is found that alcohols of the same type give values which agree closely.

Reid, ${ }^{4}$ studying the mechanism of the reaction in esterification, employed mercaptans instead of alcohols, in order to distinguish between the $(\mathrm{OH})$ or $(\mathrm{SH})$ group of the acid and that of the alcohol. He showed, conclusively, that the $(\mathrm{OH})$ group of the acid is eliminated with the $(\mathrm{H})$ of the mercaptans as water, also that the reverse reaction, starting with the ester and water, yields the oxygen acid and mercaptan, as follows:

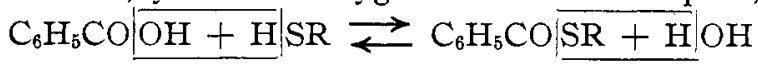

I J. prakt. Chem., [2] 29, 437-47 (1884).

${ }^{2}$ Compt. rend., 152, 495 (19II).

I Am. Chem. Pharm., [3] 68, 268 (1863).

${ }^{2}$ Am. Chem. J., 43, 489 (1910). 
Reid also showed that the reaction reaches a well-defined limit, which confirms the original idea that mercaptans are true analogs of alcohols. He carried out a number of experiments, using benzoic acid with ethyl mercaptan, and found the limit to be at about $16.8 \%$, which is much lower than the limit with alcohols. His work was preliminary, and his object was to establish the existence of the limit rather than to find its exact location. He did not extend the work to other mercaptans.

The present work was taken up to study more thoroughly the relations between mercaptans and alcohols, to determine whether the limits, for a series of mercaptans, follow relations observed with alcohols, and to discover, if possible, whether the limits are in any way dependent on temperature.

It should be pointed out that the difficulties encountered in this work are much greater than in the work with alcohols. In the latter case, Menschutkin, Berthelot and Pean de St. Gilles, and others, used constant proportions of alcohol and acid in a series. The mixture was prepared, and then definite amounts of it were sealed into the reaction tubes. Also, in analyzing the reaction mixture, the presence of alcohol need not be avoided. However, in working with mercaptans the proportions of active materials were widely varied, it being impossible to employ a mercaptan solution of the acid without very great loss due to the high vapor tensions of the mercaptans. Mercaptans, moreover, are acids, and can be titrated with alkali. Owing to this fact, it is necessary to eliminate the mercaptan from the reaction mixture before titration.

Such considerations make it evident that the experimental error in using mercaptans is larger than in using alcohols. On the other hand, there is a decided advantage in using varying proportions of active material, since systematic errors, which may become uniform and on that account escape notice, are thus avoided. The results obtained may not appear so accurate as those obtained by the other method, but they really mean more.

\section{Materials.}

Benzoic Acid.-The benzoic acid was a well-known firm's best grade.

Mercaptans. -The methyl and ethyl mercaptans were made by Reid for use in the work mentioned. Both were freed from sulfides, dried and distilled, only the best fractions being used in this work. The methyl mercaptan boiled at $6^{\circ}$, the ethyl at $35.5^{\circ}$ to $36.1^{\circ}$.

The propyl, isobutyl and isoamyl mercaptans were standard commercial products.

The thiol esters were made by alkylating thiol-benzoic acid, prepared according to Kym's ${ }^{1}$ general directions. The acid was, however, purified by dissolving the potassium salt in water, filtering, and liberating the

${ }^{1}$ Ber., 32, 3533 (1899). 
acid with $\mathrm{HCl}$. After settling, the oily acid was separated and the aqueous solution extracted with ether. On evaporation of the ether, the acid was ready for use in making the esters.

Methyl Thiol-benzoate.-Dimethyl sulfate was used as the alkylating agent. $79 \mathrm{~g}$. of thiol-benzoic acid were nearly neutralized with $\mathrm{KOH}$ solution. $79 \mathrm{~g}$. of dimethyl sulfate were then added slowly with vigorous shaking, and cooling. The mixture was allowed to stand several hours, and was then heated two hours under a reflux condenser, the excess dimethyl sulfate being decomposed on boiling.

The ester separated from the solution and was removed by means of a separatory funnel. The solution was made alkaline and the remaining ester extracted with ether. The ester was washed several times with water, dried over $\mathrm{CaCl}_{2}$, the ether evaporated and the ester redistilled. The ester possessed a slight green color which, however, disappeared in several months, a faint brown color remaining. $50 \mathrm{~g}$. of best fraction, $b_{25} I_{34}{ }^{\circ}$ was obtained, $d_{25}^{25}$ I.I38I. Obermeyer ${ }^{1}$ gives $b_{760} 23 I^{-2}-22^{\circ}$.

Ethyl Thiol-benzoate. -This was made according to the directions of Wheeler ${ }^{2}$ from potassium thiol-benzoate and ethyl bromide. The ester was distilled in a partial vacuum. $3 \mathrm{I} g$. of best fraction, $b_{31} \mathrm{I}_{4} 6^{\circ}$, was obtained, having a faint brown color. The density found, $\mathrm{d}_{25}^{25} \mathrm{I} .0977$, agrees well with the value found by $R e i d,{ }^{3} \mathrm{~d}_{25}^{25} \mathrm{r} .097 \mathrm{I}$, whose samples were fractionated at atmospheric pressure.

Propyl Thiol-benzoate.-This was made by the general method used by Wheeler ${ }^{4}$ in preparing the ethyl ester. The ester was carefully fractionated in a partial vacuum. $3 \mathrm{I} \mathrm{g}$. of best fraction, $b_{13} \mathrm{I} 44^{\circ}$, were obtained. The density was found to be $\mathrm{d}_{25}^{25}$ I.0724. The ester possessed a rather deep reddish brown color. Inasmuch as the method of preparation used was perfectly general, and well-known compounds employed; no analysis of the ester was made.

Water.-Conductivity water was used.

The Furnace.

An electric furnace (Fig. I) was constructed as shown in the diagram. It consists of a brass tube, $C$, surrounded by a porcelain cylinder in two sections, $B B^{\prime}$, on which is wound the resistance wire. ${ }^{5}$ The system is insulated thermally by two inches of asbestos-magnesia steam-pipe packing, $\mathrm{A} \mathrm{A}^{\prime}$. The electrical connections are so arranged as to allow the two electric units to be connected in parallel, in case more rapid heating is desired.

1 Ber, 20, 2922 (I 887 ).

${ }^{2}$ A m. Chem. J., 24, 69 (1900).

${ }^{3}$ Ibid., 43, 493 (Igro).

' Loc. cit.

The ready wound porcelain cylinders were obtained from H. G. Crane, 226 Cypress St., Brookline, Mass. 
One end of the brass tube rests against the adjustable set-screw $D$, which is placed in one end of the frame $I$. The other end presses against the short arm of the small lever $E$, the long arm of which acts against the short arm of the indicator lever $F$. The indicator lever is held in carefully adjusted cone bearings, $\mathrm{H}$, which reduce friction to a minimum. The sliding contact between the two levers was worked very smooth and, when oiled, developed no appreciable friction. As the temperature rises, the brass tube expands, operates the system of levers

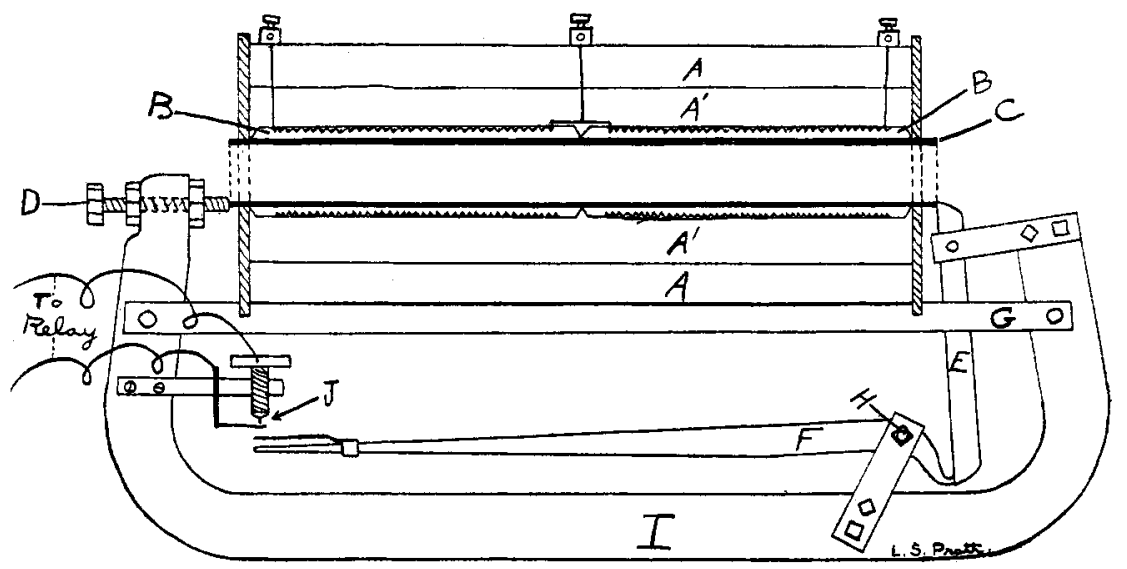

Fig. I.

(which multiplies the motion about roo times), and finally the strip of spring brass on the tip of the indicator lever closes the relay circuit by pressing the strip of platinum foil against the platinum point as shown in the apparatus $\mathrm{J}$. The relay breaks the heating current, allowing the furnace to cool till the indicator.lever drops slightly, opening the relay circuit. $G$ is a bar to strengthen the frame. The furnace is set by inserting a thermometer in the end of the tube and adjusting the set-screw till the furnace regulates at the desired temperature.

When in operation, the brass tube is fitted at each end with asbestos plugs I. 5 inches thick, and covering the whole end is a raised plate of asbestos board, insulating from radiation, all points except the point of contact of the lever, or the set-screw, and the brass tube.

This furnace has given entire satisfaction, its performance being reproduceable after long periods of inactivity. It has been used at $193^{\circ}$, $220^{\circ}, 243^{\circ}, 270^{\circ}$ and $300^{\circ}$. The temperature remained constant within a range of about $4^{\circ}$, which was sufficient for this work. Much of the variation is due to the time necessary for heat to penetrate the porcelain cylinders, which are about one-third of an inch thick.

Another furnace of somewhat similar design is in process of construc- 
tion, employing alundum cylinders instead of porcelain, and affording better insulation, particularly at the ends of the tube. It is hoped that this furnace will maintain the temperature constant within $I^{\circ}$.

\section{Standard Solutions.}

The standard barium hydroxide was. kept in a large stock bottle from which it was run through a siphon, with a stopcock, into the buret. The top of the buret and the stock bottle were protected from the carbon dioxide of the air by soda-lime tubes. The absence of any appreciable amount of $\mathrm{BaCO}_{3}$ in the top of the buret, after five months' use of this apparatus, showed that the protection was adequate.

A similar system was used for the $\mathrm{HCl}$ solution, except that the vents were protected by tubes containing $\mathrm{HCl}$ solution.

Both solutions were approximately O.I $N$, and were standardized frequently.

\section{Procedure.}

Hard glass tubes about $6 \times 75 \mathrm{~mm}$., closed at one end, were boiled for six hours in dilute $\mathrm{HCl}$, one hour in distilled water, and then thoroughly dried.

Acid Series.-Each tube was weighed, partly filled with benzoic acid, drawn out to a narrow neck and weighed again. The mercaptan was then introduced, the tube being cooled in ice and salt, and the tube sealed. The tube and the tip were then weighed.

Ester Series.-Each tube was weighed, partly filled with thiol-ester, drawn out and weighed again. One or two small drops of very pure water were then added and the tube sealed. The tube and the tip were then weighed. After being heated sufficiently in the furnace, and cooled, the tubes were ready for analysis. A tube was scratched with a file, kept for a time in a test-tube surrounded with ice and salt, to reduce pressure due to the vapor tension of the mercaptan, quickly broken, and the parts dropped into a I20 cc. Erlenmeyer flask. About $20 \mathrm{cc}$. of alcohol (distilled from $\mathrm{KOH}$ ) were added to dissolve the reaction mixture.

The mercaptan was then "blown off" by passing a current of air (free from $\mathrm{CO}_{2}$ ) through the solution for fifteen minutes, the solution being heated by immersing the flask in a large beaker of water kept at $50^{\circ}$.

The benzoic acid in the solution was then titrated with standard $\mathrm{Ba}(\mathrm{OH})_{2}$ solution using alcoholic phenolphthalein as indicator. This method of procedure was the result of a large amount of preliminary work testing the methods best adapted to eliminate or minimize the sources of error in each operation. It was tested by subjecting weighed amounts of benzoic acid, with and without added mercaptan, to the same treatment and then titrating. Correct results were thus obtained. 


\section{Experimental.}

Since, ${ }^{1}$ according to the usual reasoning in the consideration of reversible reactions, the amount of ester formed in unit time is equal to (benzoic acid) (mercaptan) $\mathrm{K}$, and the amount of ester decomposed in the same time is equal to (water) (ester) $K^{\prime}$ (the expressions in parentheses represent concentrations), and since, at equilibrium, these opposing velocities are equal, we have:

$$
\frac{\text { (Benzoic acid) (Mercaptan) }}{\text { (Water) (Ester) }}=\frac{\mathrm{K}^{\prime}}{\mathrm{K}}=r
$$

For equal concentrations of acid and mercaptan at equilibrium,

or

$$
\frac{\text { Amount of mixture unesterified }}{\text { Amount of mixture esterified }}=\frac{\sqrt{\overline{\mathrm{K}}^{\prime}}}{\sqrt{\overline{\mathrm{K}}}}=\frac{\sqrt{r}}{\mathrm{I}}
$$

$$
\frac{\text { Amount of mixture esterified }}{I}=\frac{100}{\sqrt{r}+I} \cdot{ }^{2}
$$

In percentages this becomes:

Percentage of mixture of equivalent amounts, esterified at limit, $=\frac{\text { IOO }}{\sqrt{r}+I}$

This value is given in the last line in the following tables.

Preliminary experiments were carried out to determine the temperatures to be used, and the time necessary for the reactions to reach equilibrium. The results obtained for short periods of time were irregular and are not included in the tables, but the average results are of some interest and are plotted below in the form of a curve (Fig. 2). The temperature is not accurately known, as the thermometer used in setting the furnace was later found to be defective; but it was about $200^{\circ}$. The curve shows, roughly, the decrease in velocity as the reactions approach equilibrium.

Series I, II, III and IV are represented complete in tabular form, the methyl, ethyl, propyl, isobytyl and isoamyl series being arranged in the order named.

In tabulating the results, the data involved are arranged as follows:

$a$, Acid or ester in grams.

$b$, Millimols of acid or ester.

$c$, Mercaptan or water in grams.

$d$, Millimols of mercaptan or water.

$e$, Cubic centimeters of alkali (0.092 10 $N$ ) required for titration.

$f$, Millimols of acid present calculated from $e$. In ester series this equals mercaptan.

1 Reid, Am. Chem. J., 43, 499 (19ro); see also Bonz, Z. physik. Chem., 2, 865 (1888).

2 By a typographical error, this is printed in Reid's paper as $100 / \sqrt{r}-1$, but his results were all calculated by the correct formula. 
g, Millimols mercaptan remaining (in acid series).

$h$, Millimols ester remaining (in ester series).

$k$, Millimols water $=$ remaining (in ester series).

$m$, Millimols ester $=$ water (in acid series).

$\%$, percentage esterification. This is calculated, by formula deduced above, for equivalent concentrations of acid and mercaptan or ester and water.

In acid series, in which the start is made with acid and mercaptan, the amount of ester given $(m)$ is found by subtracting the acid remaining $(f)$ from $(b)$ the original acid. The concentration of ester $(m)$ equals

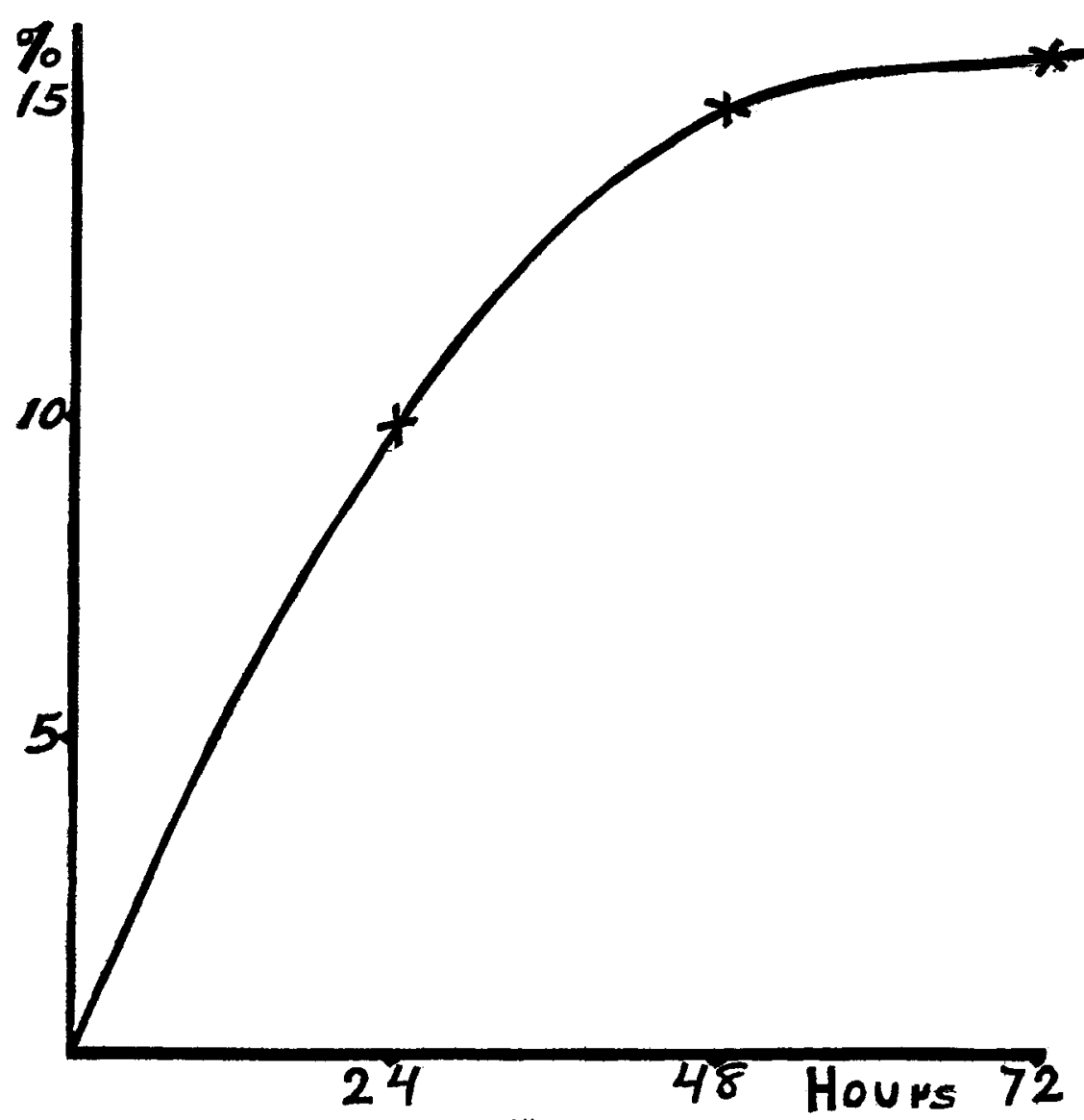

Fig. 2.

the concentration of water. The millimols of mercaptan remaining, as given in $(g)$, is obtained by subtracting the amount of ester $(m)$ from $(d)$ the mercaptan originally present. 
In the ester series, starting with ester and water, the amount of ester given $(h)$ is found by subtracting the acid present $(f)$ from $(b)$ the original ester. The water remaining $(k)$ is obtained by subtracting the acid present $(f)$ from $(d)$ the original water.

All the figures given, except those represented by $a, c, e, \sqrt{r}$ and $\%$, are in millimols.

The tables for corresponding acid and ester series are lettered as follows: Acid series $A, B$, etc., ester series $A^{\prime}, B^{\prime}$, etc.

Bracketed results are not used in calculating the limits.

TABLE A. $-\mathrm{C}_{6} \mathrm{H}_{5} \mathrm{COOH}+\mathrm{CH}_{3} \mathrm{SH}$.

67 hours at $193^{\circ}$ and 168 hours at $243^{\circ}$.

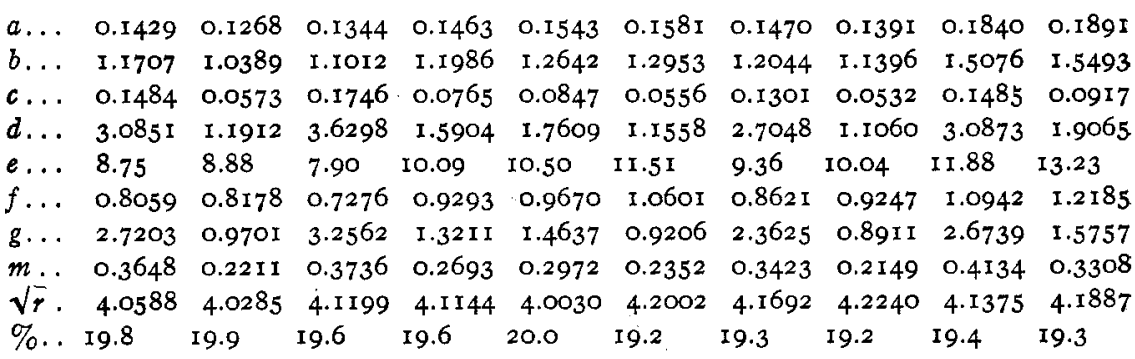

Average, $19.5 \%$.

TABLE $\mathrm{A}^{\prime}$. $-\mathrm{C}_{6} \mathrm{H}_{5} \mathrm{COSCH}_{3}+\mathrm{H}_{2} \mathrm{O}$.

67 hours at $193^{\circ}$ and 168 hours at $243^{\circ}$.

\begin{tabular}{|c|c|c|c|c|c|c|c|c|c|c|}
\hline & & & & & & & & & & \\
\hline & 2.2 & I.9000 & I. $667 \mathrm{I}$ & 1.9152 & 1.7224 & I. 7822 & I. 9238 & I.7414 & & \\
\hline & .0512 & 0.0571 & $0.055^{1}$ & 75 & & 90 & & 445 & & \\
\hline & & & & & & & & & & \\
\hline & 21.00 & 19.02 & I6.78 & I 7.64 & 7. & 17.68 & 18.9 & 17. & & \\
\hline & 1.9894 & I.75 & I.545 & 1.6246 & & 1.6284 & & & & \\
\hline & & & & & & & & & & \\
\hline & .054 & & & & & 36 & 1.0766 & 0.8989 & & \\
\hline & & & 3.5987 & & & & & & & \\
\hline & & 0.7 & 21.7 & 18.3 & 20.3 & 18.7 & 20.0 & Ig. 8 & 20.0 & $2 I .9$ \\
\hline
\end{tabular}

Average, $20.1 \%$. Limit from $\mathrm{A}$ and $\mathrm{A}^{\prime}, 19.6 \%$.

TABLE B. $-\mathrm{C}_{6} \mathrm{H}_{5} \mathrm{COOH}+\mathrm{CH}_{3} \mathrm{SH}$. I68 hours at $220^{\circ}$.

$\begin{array}{lllllll}a \ldots \ldots \ldots \ldots \ldots & 0.1527 & 0.1394 & 0.1325 & 0.1485 & 0.1369 & 0.148 \mathrm{I} \\ b \ldots \ldots \ldots \ldots & 1.2511 & 1.1421 & 1.0856 & 1.2167 & 1.1216 & 1.2134 \\ c \ldots \ldots \ldots \ldots & 0.1939 & 0.1875 & 0.1233 & 0.1182 & 0.1633 & 0.1506 \\ d \ldots \ldots \ldots \ldots \ldots & 4.0312 & 3.8981 & 2.5634 & 2.4574 & 3.3950 & 3.1310 \\ e \ldots \ldots \ldots \ldots & 9.23 & 8.30 & 8.42 & 9.73 & 8.37 & 9.38 \\ f \ldots \ldots \ldots \ldots & 0.8301 & 0.7644 & 0.7755 & 0.8961 & 0.7709 & 0.8639 \\ g \ldots \ldots \ldots \ldots & 3.6302 & 3.5204 & 2.2533 & 2.1368 & 3.0443 & 2.7816 \\ m \ldots \ldots \ldots \ldots & 0.4010 & 0.3777 & 0.3101 & 0.3206 & 0.3507 & 0.3495 \\ \sqrt{r} \ldots \ldots \ldots \ldots & 4.4317 & 4.3431 & 4.2629 & 4.3162 & 4.3682 & 4.4353 \\ \% \ldots \ldots \ldots \ldots & 18.4 & 18.7 & 19.0 & 18.8 & 18.6 & 18.4\end{array}$

Average, $18.6 \%$. 
TABLE B. $-\mathrm{C}_{6} \mathrm{H}_{5} \mathrm{COSCH}_{3}+\mathrm{H}_{2} \mathrm{O}$.

I68 hours at $220^{\circ}$.

\begin{tabular}{|c|c|c|c|c|c|c|}
\hline$a \ldots \ldots \ldots \ldots$ & 0.2923 & 0.1887 & 0.2192 & 0.2756 & 0.2413 & 0.3137 \\
\hline$b \ldots \ldots \ldots \ldots$ & 1.9230 & I. 2414 & I , $442 \mathrm{I}$ & I. 8132 & I. 5875 & 2.0638 \\
\hline$c \ldots \ldots \ldots \ldots$ & 0.0776 & 0.0532 & $0.034 \mathrm{I}$ & 0.0338 & 0.0291 & 0.0436 \\
\hline$d \ldots \ldots \ldots \ldots$ & $4 \cdot 3106$ & $2.955^{2}$ & I. $894^{2}$ & I. 8776 & 1.6165 & 2.4220 \\
\hline$e \ldots \ldots \ldots$ & 19.80 & I 2.91 & 14.00 & 16.60 & $14.5^{2}$ & 19.60 \\
\hline$f \ldots$ & 1.8236 & I. 1890 & I. 2894 & 1.5289 & I. 3373 & 1.8052 \\
\hline$h \ldots$ & 0.0994 & 0.0524 & 0.1527 & 0.2843 & 0.2502 & 0.2586 \\
\hline$k \ldots$ & 2.4870 & I. 7662 & 0.6048 & $0.34^{8} 7$ & 0.2792 & 0.6168 \\
\hline$\sqrt{r}$. & 3.6677 & 3.9084 & 4.2430 & $4.855^{8}$ & 5.0597 & 4.5200 \\
\hline$\% \ldots \ldots$ & $2 \mathrm{I}, 4$ & 20.4 & 19.1 & 17.1 & 16.5 & 18.2 \\
\hline
\end{tabular}

Average, $18.8 \%$. Limit from $\mathrm{B}$ and $\mathrm{B}^{\prime}, \mathrm{1} 8.7 \%$.

TABLE C. $-\mathrm{C}_{6} \mathrm{H}_{6} \mathrm{COOH}+\mathrm{C}_{2} \mathrm{H}_{5} \mathrm{SH}$.

240 hours at $193^{\circ}$ and $\mathrm{I} 68$ hours at $243^{\circ}$.

\begin{tabular}{|c|c|c|c|c|c|c|c|c|c|}
\hline & & & & & & & & & \\
\hline & & & & & & & & & \\
\hline & & & & & & & & & \\
\hline & & & & & & & & & \\
\hline & & 12.9 & $\tau_{n}$ & 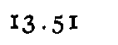 & 15. & 10. 96 & $\mathrm{r}_{5}$. & 14 & \\
\hline & & & & & & I .0094 & & & \\
\hline & & & 904 & & & & & & \\
\hline & 0.2548 & 0.2585 & 0.2266 & & & & & & \\
\hline & 5.6226 & 5.6110 & 5.4793 & 5.6844 & 5.9193 & 5.7844 & 5.6640 & 6925 & 27 \\
\hline & & & & & & & & & \\
\hline
\end{tabular}

Average, ${ }_{15} .0 \%$. Traces of $\mathrm{H}_{2} \mathrm{~S}$.

TABLE $\mathrm{C}^{\prime} .-\mathrm{C}_{6} \mathrm{H}_{6} \mathrm{COSC}_{2} \mathrm{H}_{5}+\mathrm{H}_{2} \mathrm{O}$.

240 hours at $193^{\circ}$ and $\mathrm{I} 68$ hours at $243^{\circ}$.

\begin{tabular}{|c|c|c|c|c|c|c|c|c|c|c|}
\hline & & & & & & & & & & \\
\hline & & & & & & & & & & \\
\hline & & & & & & & & & & \\
\hline & & & & & & & & & & \\
\hline & $2 C$ & 1.3 & & .c & & I 8. & & 22. & & \\
\hline & 20 & & & 2.0 & & & & 492 & & \\
\hline & & & & & & & & & & \\
\hline & I. 4543 & 0.91 & I. $800 \mathrm{I}$ & 2.3817 & I.I IO9 & $0.4 I_{4} 6$ & 1.8453 & 1.0616 & & \\
\hline & 4.5336 & $\begin{array}{r}5.076 \\
16.4\end{array}$ & 55 & 3.7727 & $4.734^{\circ}$ & $\begin{array}{c}5.7627 \\
4.8\end{array}$ & $\begin{array}{l}4.3248 \\
8.8\end{array}$ & & & \\
\hline
\end{tabular}

Average, $18.0 \%$. Limit from $\mathrm{C}$ and $\mathrm{C}^{\prime},{ }_{15.4 \%}$. Traces of $\mathrm{H}_{2} \mathrm{~S}$. 
TABLE D. $-\mathrm{C}_{6} \mathrm{H}_{5} \mathrm{COOH}+\mathrm{C}_{2} \mathrm{H}_{6} \mathrm{SH}$. 96 hours at $220^{\circ}$.

$\begin{array}{llllll}a & 0.2209 & 0.1613 & 0.1564 & 0.1673 \\ b & 1.8099 & 1.3215 & 1.2814 & 1.3707 \\ c & 0.1668 & 0.1647 & 0.1360 & 0.1374 \\ d & 2.6856 & 2.6517 & 2.1896 & 2.2122 \\ e & 16.19 & 11.39 & 11.30 & 12.14 \\ f & 1.4911 & 1.0490 & 1.0407 & 1.1181 \\ g & 2.3668 & 2.3792 & 1.9489 & 1.9596 \\ m & 0.3188 & 0.2725 & 0.2407 & 0.2526 \\ \sqrt{r} & 5.8927 & 5.7974 & 5.9167 & 5.8600 \\ \% & 14.5 & 14.7 & 14.5 & 14.6\end{array}$

Average, $14.6 \%$.
TABLE E. $-\mathrm{C}_{6} \mathrm{H}_{6} \mathrm{COOH}+\mathrm{C}_{2} \mathrm{H}_{5} \mathrm{SH}$. I 68 hours at $220^{\circ}$.

$\begin{array}{lllllll}0.1818 & 0.1756 & 0.2310 & 0.1873 & 0.1783 & 0.2052\end{array}$

$\begin{array}{llllllll}1.4895 & 1.4387 & 1.8926 & 1.5446 & 1.4608 & 1.6813\end{array}$

$\begin{array}{lllllll}0.1205 & 0.1166 & 0.1395 & 0.1259 & 0.1438 & 0.1354\end{array}$

$\begin{array}{lllllll}1.9402 & 1.8773 & 2.2460 & 2.027 I & 2.3153 & 2.1800\end{array}$

$\begin{array}{llllll}13.51 & 13.06 & 17.38 & 13.98 & 13.06 & 15.33\end{array}$

$\begin{array}{lllllll}1.2443 & 1.2028 & 1.6007 & 1.2875 & 1.2028 & \text { I.4II }\end{array}$

$\begin{array}{lllllll}1.6950 & 1.64 I 4 & 1.9541 & 1.7700 & 2.0573 & 1.9106\end{array}$

$\begin{array}{lllllll}0.2452 & 0.2359 & 0.2919 & 0.2571 & 0.2580 & 0.2694\end{array}$ $\begin{array}{lllllllll}5.9229 & 5.9564 & 6.0588 & 5.8719 & 6.097 \text { I } & 6.0965 .\end{array}$ $\begin{array}{llllll}14.5 & I 4.4 & 14.2 & 14.6 & \text { I4. I } & \text { I 4. I }\end{array}$

Average, $14.3 \%$.
TABLE $\mathrm{D}^{\prime} .-\mathrm{C}_{6} \mathrm{H}_{5} \mathrm{COSC}_{2} \mathrm{H}_{5}+\mathrm{H}_{2} \mathrm{O}$. 96 hours at $220^{\circ}$.

$\begin{array}{lllll}a & 0.2752 & 0.2884 & 0.2980 & 0.2828 \\ b & 1.6578 & 1.7374 & 1.7952 & 1.7036 \\ c & 0.0496 & 0.0314 & 0.0267 & 0.0330 \\ d & 2.7553 & 1.7842 & 1.4832 & 1.8331 \\ e & 16.59 & 15.93 & 14.86 & 15.98 \\ f & 1.5280 & 1.4672 & 1.3685 & 1.4717 \\ h & 0.1298 & 0.2702 & 0.4267 & 0.2319 \\ k & 1.2273 & 0.2770 & 0.1147 & 0.3614 \\ \sqrt{f} & 3.8284 & 5.3630 & 6.1861 & 5.0837 \\ \%(20.7) & 15.7 & (13.9) & 16.4\end{array}$

Average, $16 . x \%$. Limit from $D$ and $D^{\prime}, 14.8 \%$.
TABLE $\mathrm{E}^{\prime}-\mathrm{C}_{6} \mathrm{H}_{6} \mathrm{COSC}_{2} \mathrm{H}_{5}+\mathrm{H}_{2} \mathrm{O}$. I68 hours at $220^{\circ}$.

\begin{tabular}{|c|c|c|c|c|c|}
\hline 0.2310 & 0.3104 & 0.2468 & 0.2963 & 0.2489 & 0.30 \\
\hline 1.3915 & I. 8698 & I. 4867 & 1.7849 & I.4994 & 1.8331 \\
\hline 0.0330 & 0.0484 & 0.0259 & 0.0323 & 0.0379 & 0.0385 \\
\hline I. $833 \mathrm{I}$ & 2.6886 & I. 4387 & I. 7942 & 2.1054 & \\
\hline 3.71 & I 8.55 & 13.55 & I6.6o & 14.92 & 17.66 \\
\hline 1.2626 & I. 7084 & 1.2480 & 1.5289 & I.374I & $1.62 C$ \\
\hline 0.1289 & 0.1614 & 0.2387 & 0.2560 & 0.1253 & 0.2066 \\
\hline 0.5705 & 0.9802 & 0.1907 & 0.2653 & 0.7313 & $0.5 \mathrm{I}$ \\
\hline $4.656 I$ & 4.2952 & 5.8427 & 5.8666 & 4.5393 & \\
\hline & I8.8 & 14.6 & I 4.6 & 18.0 & 16.7 \\
\hline
\end{tabular}

Average, $16.7 \%$. Limit from $\mathrm{E}$ and $\mathrm{E}^{\prime}, \mathrm{I} 4.6 \%$.

TABLE F- $-\mathrm{C}_{6} \mathrm{H}_{5} \mathrm{COOH}+\mathrm{C}_{8} \mathrm{H}_{7} \mathrm{SH}$.

240 hours at $193^{\circ}$ and 168 hours at $243^{\circ}$.

$\begin{array}{llllllll}a \ldots \ldots \ldots \ldots \ldots \ldots & 0.2080 & 0.1813 & 0.1951 & 0.1615 & 0.2090 & 0.1885 & 0.1466 \\ b \ldots \ldots \ldots \ldots \ldots & 1.7042 & 1.4854 & 1.5621 & 1.3232 & 1.7124 & 1.5444 & 1.2011 \\ \ldots \ldots \ldots \ldots \ldots \ldots & 0.0523 & 0.0789 & 0.0755 & 0.0754 & 0.0794 & 0.0826 & 0.0823 \\ d \ldots \ldots \ldots \ldots \ldots & 0.6870 & 1.0364 & 0.9917 & 0.9904 & 1.0429 & 1.0849 & 1.0810 \\ e \ldots \ldots \ldots \ldots \ldots & 16.76 & 14.15 & 15.28 & 12.50 & 16.44 & 14.70 & 11.24 \\ f \ldots \ldots \ldots \ldots \ldots & 1.5436 & 1.3032 & 1.4073 & 1.1512 & 1.5141 & 1.3538 & 1.0352 \\ g \ldots \ldots \ldots \ldots \ldots & 0.5264 & 0.8542 & 0.8369 & 0.8184 & 0.8446 & 0.8943 & 0.9151 \\ m \ldots \ldots \ldots \ldots \ldots & 0.1606 & 0.1822 & 0.1548 & 0.1720 & 0.1983 & 0.1906 & 0.1659 \\ \sqrt{r} \ldots \ldots \ldots \ldots \ldots & 5.6128 & 5.7907 & 7.0104 & 5.6432 & 5.7026 & 5.7730 & 5.7333 \\ \% \ldots \ldots \ldots \ldots \ldots & 15.1 & 14.7 & (12.5) & 15.1 & 14.9 & 14.8 & 14.9\end{array}$

Average, $14.9 \%$. Traces of $\mathrm{H}_{2} \mathrm{~S}$. 
TABLE $\mathrm{F}^{\prime}-\mathrm{C}_{8} \mathrm{H}_{5} \mathrm{COSC}_{8} \mathrm{H}_{7}+\mathrm{H}_{2} \mathrm{O}$.

240 hours at $193^{\circ}$ and $\mathrm{I} 68$ hours at $243^{\circ}$.

$\begin{array}{llllllll}a \ldots \ldots \ldots \ldots \ldots \ldots & 0.3123 & 0.2846 & 0.2963 & 0.3028 & 0.2910 & 0.2121 & 0.2797 \\ b \ldots \ldots \ldots \ldots \ldots & 1.7350 & 1.5811 & 1.6461 & 1.6822 & 1.6167 & 1.1783 & 1.5539 \\ c \ldots \ldots \ldots \ldots \ldots & 0.0462 & 0.0588 & 0.0552 & 0.0621 & 0.0441 & 0.0189 & 0.0507 \\ d \ldots \ldots \ldots \ldots \ldots & 2.5664 & 3.2663 & 3.0663 & 3.4497 & 2.2498 & 1.0498 & 2.8164 \\ \ldots \ldots \ldots \ldots \ldots \ldots & 17.76 & 16.55 & 17.17 & 17.54 & 16.48 & 10.41 & 16.18 \\ f \ldots \ldots \ldots \ldots \ldots & 1.6357 & 1.5243 & 1.5814 & 1.6154 & 1.5178 & 0.9588 & 1.4902 \\ h \ldots \ldots \ldots \ldots \ldots & 0.0993 & 0.0568 & 0.0647 & 0.0668 & 0.0989 & 0.2195 & 0.0637 \\ k \ldots \ldots \ldots \ldots \ldots & 0.9307 & 1.7420 & 1.4849 & 1.8343 & 0.7320 & 0.0910 & 1.3262 \\ \sqrt{7} \ldots \ldots \ldots \ldots \ldots & 5.3805 & 4.8459 & 5.1018 & 4.6147 & 5.6410 & 6.7840 & 5.1271 \\ \% \ldots \ldots \ldots \ldots \ldots & 15.7 & 17.1 & 16.4 & 17.8 & 15.1 & (12.9) & 16.3\end{array}$

Average, $16.4 \%$. Limit from $F$ and $F^{\prime}, 15.1 \%$. Traces of $\mathrm{H}_{2} \mathrm{~S}$.

TABLE G. $-\mathrm{C}_{8} \mathrm{H}_{3} \mathrm{COOH}+\mathrm{C}_{3} \mathrm{H}_{7} \mathrm{SH}$. I 68 hours at $220^{\circ}$.

$\begin{array}{lllllll}a & 0.1946 & 0.2266 & 0.2216 & 0.1634 & 0.1625 & 0.1863 \\ b & 1.5944 & 1.8566 & 1.8156 & 1.3387 & 1.3314 & 1.5264 \\ c & 0.1302 & 0.1074 & 0.2436 & 0.1202 & 0.1038 & 0.1654 \\ d & 1.7102 & 1.4107 & 3.1998 & 1.5788 & 1.3634 & 2.1726 \\ e & 14.83 & 17.67 & 16.22 & 12.38 & 12.40 & 13.94 \\ f & 1.3658 & 1.6274 & 1.4938 & 1.1402 & 1.1420 & 1.2838 \\ g & 1.4816 & 1.1815 & 2.8780 & 1.3803 & 1.1740 & 1.9300 \\ m & 0.2286 & 0.2292 & 0.3218 & 0.1985 & 0.1894 & 0.2646 \\ \sqrt{r} & 6.2228 & 6.0500 & 6.4433 & 6.3200 & 6.1135 & 6.4887 \\ \% & 13.9 & 14.2 & 13.4 & 13.7 & 14.1 & 13.4\end{array}$

Average, $13.8 \%$. Traces of $\mathrm{H}_{2} \mathrm{~S}$.
TABLE H. $-\mathrm{C}_{6} \mathrm{H}_{5} \mathrm{COOH}+\mathrm{C}_{3} \mathrm{H}_{7} \mathrm{SH}$. 240 hours at $193^{\circ}$.

$\begin{array}{ccc}0.2186 & 0.1997 & 0.1913 \\ 1.7910 & 1.6362 & 1.5674 \\ 0.0627 & 0.0860 & 0.0443 \\ 0.8236 & 1.1296 & 0.5819 \\ 17.63 & 15.66 & 15.57 \\ 1.6237 & 1.4423 & 1.4340 \\ 0.6563 & 0.9357 & 0.4485 \\ 0.1673 & 0.1939 & 0.1334 \\ 6.1701 & 5.9913 & 6.0115 \\ 13.9 & 14.3 & 14.2\end{array}$

Average, 14. I\%
TABLA $\mathrm{G}^{\prime}-\mathrm{C}_{6} \mathrm{H}_{5} \mathrm{COSC}_{3} \mathrm{H}_{7}+\mathrm{H}_{2} \mathrm{O}$. I 68 hours at $220^{\circ}$.

$\begin{array}{lllllll}a & 0.3185 & 0.2992 & 0.2333 & 0.3138 & 0.2452 & 0.2431 \\ b & 1.7694 & 1.6622 & 1.2961 & 1.7433 & 1.3622 & 1.3505 \\ c & 0.0456 & 0.0642 & 0.0511 & 0.0255 & 0.0357 & 0.0320 \\ d & 2.5330 & 3.5663 & 2.8386 & 1.4165 & 1.9832 & 1.7776 \\ e & 18.08 & 17.44 & 13.60 & 14.54 & 13.93 & 13.64 \\ f & 1.6652 & 1.6062 & 1.2525 & 1.3391 & 1.2829 & 1.2562 \\ h & 0.1042 & 0.0560 & 0.0436 & 0.4042 & 0.0793 & 0.0943 \\ k & 0.8678 & 1.9601 & 1.5861 & 0.0774 & 0.7003 & 0.5214 \\ \sqrt{r} & 5.5375 & 4.8480 & 4.7630 & 7.5707 & 5.4443 & 5.6653 \\ \% & 15.3 & 17.1 & 17.4 & (11.7) & 15.5 & 15.0\end{array}$

Average, $16.1 \%$. Limit from $G$ and $G^{\prime}, 14.1 \%$. Traces of $\mathrm{H}_{2} \mathrm{~S}$.
TABLE $\mathrm{H}^{\prime}-\mathrm{C}_{6} \mathrm{H}_{5} \mathrm{COSC}_{8} \mathrm{H}_{7}+\mathrm{H}_{2} \mathrm{O}$. 240 hours at $193^{\circ}$.

$\begin{array}{lll}0.2694 & 0.3268 & 0.2817\end{array}$

I. 4966 I. 8 I 55 I .5650

$\begin{array}{llll}0.0466 & 0.0648 & 0.0596\end{array}$

$\begin{array}{llll}2.5886 & 3.5996 & 3.3108\end{array}$

$\begin{array}{lll}15.56 & 18.98 & 16.45\end{array}$

I. 433 I I.748I I.5I5I

$\begin{array}{llll}0.0635 & 0.0674 & 0.0499\end{array}$

I. $5555 \quad$ I.85I5 I.7957

$\begin{array}{llll}5.2905 & 5.5522 & 5.0613\end{array}$

$\begin{array}{lll}15.9 & 15.3 & 16.5\end{array}$

Average, $15.6 \%$. Limit

from $\mathrm{H}$ and $\mathrm{H}^{\prime}, \mathrm{I} 4.3 \%$. 


\section{TABLE I. $-\mathrm{C}_{6} \mathrm{H}_{5} \mathrm{COOH}+\mathrm{Me}_{2} \mathrm{CH} . \mathrm{CH}_{2} \mathrm{SH}$.}

67 hours at $193^{\circ}$ and 168 hours at $243^{\circ}$.

$\begin{array}{lllllllllll}a \ldots & 0.1458 & 0.1341 & 0.1923 & 0.1562 & 0.1680 & 0.1701 & 0.1953 & 0.1519 & 0.1876 & 0.1849 \\ b \ldots & 1.1945 & 1.0987 & 1.5756 & 1.2797 & 1.3764 & 1.3936 & 1.6002 & 1.2445 & 1.5379 & 1.5150 \\ c \ldots & 0.0717 & 0.0818 & 0.0872 & 0.0596 & 0.1098 & 0.0832 & 0.0989 & 0.1664 & 0.1157 & 0.1221 \\ d \ldots & 0.7953 & 0.9073 & 0.9672 & 0.6611 & 1.2178 & 0.9228 & 1.0969 & 1.8456 & 1.2832 & 1.3543 \\ e \ldots & 11.58 & 10.48 & 15.43 & 12.70 & 13.25 & 13.52 & 15.43 & 11.61 & 15.00 & 14.54 \\ f \ldots & 1.0665 & 0.9652 & 1.4211 & 1.1696 & 1.2203 & 1.2452 & 1.4211 & 1.0692 & 1.3815 & 1.3391 \\ g \ldots & 0.6673 & 0.7738 & 0.8127 & 0.5510 & 0.0617 & 0.7744 & 0.9178 & 1.6703 & 1.1268 & 1.1784 \\ m \ldots & 0.1280 & 0.1335 & 0.1545 & 0.1101 & 0.1561 & 0.1484 & 0.1791 & 0.1753 & 0.1564 & 0.1759 \\ \sqrt{r} . & 6.5907 & 6.4735 & 6.9557 & 7.2914 & 7.2919 & 6.6172 & 6.3765 & 7.6234 & 7.9776 & 7.1414 \\ \% \ldots & 13.2 & 13.4 & 12.6 & 12.1 & 12.1 & 13.1 & 13.5 & 11.6 & 11.1 & 12.3\end{array}$

Average, $12.5 \%$. Traces of $\mathrm{H}_{2} \mathrm{~S}$. Limit, $12.7 \%$.

TABLE I'- $-\mathrm{C}_{6} \mathrm{H}_{5} \mathrm{COOH}+\mathrm{Me}_{2} \mathrm{CH} \cdot \mathrm{CH}_{2} \mathrm{CH}_{2} \mathrm{SH}$.

67 hours at $193^{\circ}$ and 168 hours at $243^{\circ}$.

\begin{tabular}{|c|c|c|c|c|c|c|c|c|c|c|}
\hline & 0.1909 & 0.1776 & 0.1925 & 0.2190 & 0.2139 & 0.1896 & 0.2319 & 0.1662 & 0.2354 & 0.1727 \\
\hline$b$ & $1.564 I$ & $1.455 \mathrm{I}$ & $1.577^{2}$ & I. 7943 & 1.7526 & I. 5534 & 1.9000 & 1.3617 & 1.9287 & 1.4150 \\
\hline & 0.1022 & 0.0957 & 0.1394 & 0.0802 & 0.1107 & 0.0794 & 0.1271 & 0.0766 & 0.1126 & $0.146 I$ \\
\hline & 0.9812 & 0.9188 & I. 3383 & 0.7700 & I. .0627 & 0.7623 & I.2202 & 0.7354 & 1.0810 & 1.4026 \\
\hline$e$ & I 3.25 & 12.31 & I 2.53 & 16.42 & I 5.03 & I 3.77 & I6.1 2 & I 2.II & 16.90 & 10.65 \\
\hline & I.2203 & I.I 337 & I. 1540 & 1.5123 & I. 3842 & $\mathrm{x} .2682$ & I. 4846 & I. I I 53 & $x .5565$ & 0.9809 \\
\hline$h$. & 0.6374 & 0.5974 & $0.915 \mathrm{I}$ & $0.4^{880}$ & 0.6943 & $0.477 I$ & 0.8048 & 0.4890 & 0.7088 & 0.9685 \\
\hline$k$. & 0.3438 & 0.3124 & 0.4232 & 0.2820 & 0.3684 & 0.2852 & 0.4144 & 0.2464 & 0.3722 & $0.434^{3}$ \\
\hline & 8. I1 20 & 8.0974 & 7.6787 & 9.6333 & 8.4152 & 8.6247 & 8.3210 & 9.4779 & 8.9239 & 7.100 \\
\hline 0 & I I.O & II.O & II. 5 & 9.4 & 10.6 & 10.4 & 10.7 & 9.5 & IO.I & 12.3 \\
\hline
\end{tabular}

Average, ro.6\%. Traces of $\mathrm{H}_{2} \mathrm{~S}$. Limit, 10.8\%.

\section{Discussion of Results.}

On examination of the foregoing results, it is evident that, while very concordant values are obtained from the acid series, those obtained from the ester series show wide variations. This was noted early in the work, and an attempt was made to discover the reason. Great care was exercised in the preparation of the tubes, and in some of the later work the furnace was rocked frequently to insure more thorough mixing in the tubes, but the variations were not eliminated. This feature of the problem will be investigated further.

It is evident that in all of the series the reaction nearly reached the limit, the values from acid and ester series differing in most cases by less than $2 \%$. This is especially important in considering the isobutyl and isoamyl series, inasmuch as in these cases no ester series was run. However, since in the other series, heated the same length of time at the same temperature, the reaction went nearly to the limit, it is reasonable to assume that in these series also the limit was very nearly reached. On this assumption, the limits for these two series are set fairly definitely. 
One point of particular interest, as shown more clearly in the table below which sums up all the results, is in regard to the relative stability of the esters, inasmuch as it is believed from this work that the ester is the substance which undergoes decomposition. It will be noted that no decomposition was detected in the tubes containing methyl esters at $243^{\circ}$. In the case of the ethyl ester slight decomposition was found in tube heated at $243^{\circ}$, but none in tubes heated at $220^{\circ}$, while in the case of the propyl ester slight decomposition was found at $220^{\circ}$. It should be stated that only slight traces of $\mathrm{H}_{2} \mathrm{~S}$ were found in tubes heated at any temperature below $270^{\circ}$, but at this temperature, in the ethyl series, decomposition took place to an extent that completely vitiated the results. The values obtained were not tabulated.

It appears, from these facts, that the stability of the esters, in this homologous series, decreases steadily with increase in molecular weight. In a series of six tubes heated at $300^{\circ}$, five exploded, and the contents of the sixth showed very strong decomposition, being nearly black. As pointed out in the introduction, the limits reached in a homologous series of alcohols may be plotted in a curve, with ethyl alcohol at the minimum, the limits ascending with increase in molecular weight, on the one hand, and methyl alcohol reaching an abnormally high limit, on the other. The results for various mercaptans tabulated below, Table J, show that with the mercaptans the limit is higher for methyl than for ethyl, but the limit, instead of rising for higher molecular weights, seems to decrease slightly.

The isobutyl and isoamyl limits can hardly be plotted as representative of higher molecular weights in this connection, as forked-chain compounds are not strictly comparable to normal compounds.

Table J.-Limits at Various Temperatures with Various Mercaptans.

$\begin{array}{cccccc}\text { Temperature. } & \text { Methyl. } & \text { Ethy1. } & \text { Propyl. } & \text { Isobutyl. } & \text { Isoamyl. } \\ 193^{\circ} & \ldots & \ldots & 14.3 & \ldots & \ldots \\ 220^{\circ} & 18.7 & 14.7 & 14.1^{1} & \ldots & \ldots \\ 243^{\circ} & 19.6 & 15.4^{1} & 15.1^{1} & 12.7^{1} & 10.8^{1} \\ 270^{\circ} & \ldots & \ldots 0^{\circ} & \ldots & \ldots & \ldots \\ 300^{\circ} & \ldots & .^{3} & \ldots & \ldots & \ldots\end{array}$

The data are not extensive enough to show conclusively the influence of temperature on the limit, but so far as the observations go, the limits are higher for higher temperatures, the elevation being of the same order and in the same direction as in the results quoted for the alcohols.

By examining the data in the various tables it will be seen that the proportions of acid and mercaptan, or ester and water, used have no appreciable influence on the limit.

${ }^{1}$ Slight decomposition. Lead acetate papers showed trace of hydrogen sulfide.

${ }^{2}$ Considerable decomposition.

${ }^{3}$ Complete decomposition. 


\section{Conclusions.}

(I) It has been conclusively shown that the mercaptans are entirely analogous to the alcohols in esterification.

(2) The limits obtained, using mercaptans, follow, in general, relations observed using alcohols, but are much lower.

(3) The reactions between methyl, ethyl and propyl mercaptans and benzoic acid, and between the thiol-esters and water at $220^{\circ}$ may be represented as follows:

(I) Acid + mercaptan $\underset{r}{\stackrel{1}{\rightleftarrows}}$ ester + water.

(2) $\mathrm{C}_{6} \mathrm{H}_{6} \mathrm{COOH}+\mathrm{CH}_{3} \mathrm{SH} \underset{18.9}{\stackrel{1}{\rightleftarrows}} \mathrm{C}_{6} \mathrm{H}_{5} \mathrm{COCSH}_{3}+\mathrm{HOH}$.

(3) $\mathrm{C}_{6} \mathrm{H}_{5} \mathrm{COOH}+\mathrm{C}_{2} \mathrm{H}_{5} \mathrm{SH} \underset{33.6}{\stackrel{1}{\rightleftarrows}} \mathrm{C}_{6} \mathrm{H}_{5} \mathrm{COSC}_{2} \mathrm{H}_{5}+\mathrm{HOH}$.

(4) $\mathrm{C}_{6} \mathrm{H}_{5} \mathrm{COOH}+\mathrm{C}_{3} \mathrm{H}_{7} \mathrm{SH} \underset{36.6}{\stackrel{1}{\rightleftarrows}} \mathrm{C}_{6} \mathrm{H}_{5} \mathrm{COSC}_{3} \mathrm{H}_{7}+\mathrm{HOH}$.

(4) The stability of the esters was found to decrease with increase in molecular weight.

(5) The limit was found to be independent of the proportions of the reacting substances.

(6) The limits were found to ascend gradually with rise in temperature.

This work will be extended to other mercaptans and to other acids, and will include a study of secondary and tertiary mercaptans. The latter phase should prove to be of special interest on account of the relations observed using secondary and tertiary alcohols.

JOHNS HOPRINS UNIVERSITY,

BALTIMORE, MD.

\section{PHENOLQUINOLINEIN, A HETEROCÝCLIC ANALOG OF PHENOLPHTHALEIN.}

By ARthur W. Dox.

Received June 19, 1915.

The similarity in behavior of quinolinic acid and phthallic acid was pointed out by Bernthsen and Mettegang ${ }^{1}$ in 1887 . These investigators showed that quinolinic anhydride reacts with benzene in the presence of aluminium chloride, according to the Friedel-Crafts reaction, to form benzoylpyridine carboxylic acid, just as phthallic acid under similar conditions yields benzoylbenzoic acid. They succeeded also in preparing. a condensation product of quinolinic anhydride with resorcin, corresponding to fluorescein, which they named fluorazein. Like fluorescein it was strongly fltorescent, and on treatment with bromine it yielded an eosinlike dye.

1 Ber., 20, 1208 (1887). 